Corina E. Brown*, Dalal Alrmuny, Mia Kim Williams, Ben Whaley and

Richard M. Hyslop

\title{
Visualizing molecular structures and shapes: a comparison of virtual reality, computer simulation, and traditional modeling
}

https://doi.org/10.1515/cti-2019-0009

Received July 6, 2019; accepted July 7, 2020; published online August 15, 2020

\begin{abstract}
The purpose of this study was to compare the effectiveness of three methods used to assist in teaching molecular geometry to college chemistry students. A pre- and post-test quasi-experiment was used to collect data about students' performance in a given chemistry exercise. One research question was intended to evaluate and compare the effectiveness of the three methods in assisting students to understand the topic and carry out the exercise correctly, and a second research question addressed students' attitudes towards the use of Virtual Reality (VR) in chemistry education. Results show a positive attitude towards the use of VR as an assisting tool to aid in understanding chemistry concepts. While the difference among the three methods was not significant, the results show that the VR brought more enthusiasm and positive attitudes toward the topic of molecular geometry among the students. Educational implications and recommendations for future research are presented as well.
\end{abstract}

Keywords: chemical education; molecular modeling; simulations; virtual reality; visualization.

\section{Introduction}

Since Chemistry is a conceptual subject, instructors typically use models to not only explain many of the concepts but also describe and relate the submicroscopic world to the macroscopic properties of matter (Taber, 2002). One way in which instructors introduce chemistry concepts to students is through the use of twodimensional representations and static three-dimensional models of three-dimensional processes. An important area of research in chemical education concerns to what extent students' interpretation of chemistry representations correspond to those meanings intended by the instructor. It is important for chemistry students to develop visual literacy and spatial ability (Harle \& Towns, 2011).

Spatial ability is the capacity to understand, reason, and remember the spatial relations among objects or space. Students use their spatial abilities to translate chemical formulas into molecular structures and to create visual multi-dimensional images of these structures mentally in their minds. These images are important to differentiate among the molecular structural configurations (Merchant et al., 2013; Oliver-Hoyo \& BabiloniaRosa, 2017). Empirical studies have explored the relationship between spatial ability and students'

Article note: Correction made after first publication: The authors Dalal Alrmuny and Mia Kim Williams were added on 8 June 2021 upon request of the editor and other authors after the article was published online.

*Corresponding author: Corina E. Brown, Department of Chemistry and Biochemistry, University of Northern Colorado, 50120 th st, Greeley, CO, USA, E-mail: corina.brown@unco.edu

Dalal Alrmuny, Technology, Innovation, and Pedagogy, College of Education and Behavioral Sciences, University of Northern Colorado, Greeley, CO, USA

Mia Kim Williams, Counseling, Leadership, Advocacy, and Design, College of Education, University of Wyoming, Laramie, WY, USA Ben Whaley and Richard M. Hyslop, Department of Chemistry and Biochemistry, University of Northern Colorado, Greeley, CO, USA

2 Open Access. (c) 2020 Corina E. Brown et al., published by De Gruyter. (c) BY This work is licensed under the Creative Commons Attribution 4.0 International License. 
performance and achievement and concluded that a positive correlation between students' achievement in organic chemistry and their spatial ability exists (Pribyl \& Bodner, 1987)

Visual literacy is the ability to read and interpret external representations and create and manipulate one's own external representations (Arneson \& Offerdahl, 2018; Towns, Raker, Becker, Harle, \& Sutcliffe, 2012). Visual literacy skills are important for chemistry and biochemistry students to understand the structures and functions of molecules from various external representations (Harle \& Towns, 2012). Chemical phenomena are not obvious without the use of visualization. The mental models of the phenomena require the existence of visualization tools such as molecular modeling programs (Jones, Jordan, \& Stilling, 2005). Virtual reality (VR) is an immersive 3-D technology that provides the user with the opportunity to experience a simulated environment that looks "authentic" and "real" (Freina \& Ott, 2008). Virtual Reality provides interactive, multidimensional visualizations that educators could utilize in chemistry education.

In order to explore the effectiveness of the utility of VR in chemistry education, we carried out a quasiexperiment with pre- and post-tests to compare three groups based on their use of a given tool: VR, simulation, and physical models. We used a convenience sampling to assign participants to each group.

This study is needed to explore the value of using VR technology in helping students learn challenging concepts in chemistry such as molecular geometry. In the existing literature, there is a lack of such studies since the idea of utilizing VR in education is relatively new. While there is a good amount of published studies that push towards utilizing VR in education (Wu \& Shah, 2004; Georgiou, Dimitropoulos, \& Manitsaris, 2007), these studies do not provide empirical evidence that can guide researchers and educators in this direction. The confirmation of the value of utilizing VR in education can guide technology companies to provide their products to schools and universities.

The findings of this study can establish empirical evidence (or counter evidence) of the value of utilizing VR in chemistry education. Other researchers can refer to this study as a starting point to move forward in the adoption of VR in chemistry education or try to look for alternative solutions. Educators as well can benefit from this study in designing their curriculum and instruction.

\section{Background of the study}

The fact that molecular geometry of molecules is difficult to visualize makes chemistry a subject challenging to study. Additionally, people see different things when viewing complex structures: what one sees depends on one's background in chemistry and preparation. "An understanding of the concepts of atom and molecule is fundamental to the learning of chemistry. Any misconceptions and alternative conceptions that students harbor about these concepts will impede further learning.” (Griffiths \& Preston, 1992)

Students learn science through a process of constructing, interpreting, and modifying their own representations of reality based on their experiences. According to the constructivist theory of learning, students will try to incorporate the mental representations of objects and concepts, along with the details provided by their instructor, thus adapting their prior knowledge to ultimately build their own understanding (Piaget, 2001). Students generate their own mental images when they hear the material presented in class or reading a text. Development of molecular visualization techniques can be seen as scaffolding methods and are based on constructivism and educational technology design (Clark \& Mayer, 2008). In chemistry education, instructors use models to describe submicroscopic elements of matter and interactions that learners cannot see with their naked eye (Taber, 2002), and the use of visualization and development of visualization techniques is "the key to understanding chemistry concepts" (Jones \& Kelly, 2015).

A multitude of studies have emphasized the benefits of including physical models, computer models, and animations into the chemistry curriculum (Abraham, Varghese, \& Tang, 2010; Claus \& Nelsen, 2009; Dori \& Barak, 2001; Jones, 2001; Pfennig \& Frock, 1999; Ruddick, Parrill, \& Petersen, 2012; Sanger, Phelps, \& Fienhold, 2000; Wu, Krajcik, \& Soloway, 2001). It was concluded that students who were provided with 3-D models as physical models, computer models or even photographs of physical models performed better on the 'Chemical Visualization Test' than students who were provided only with 2-D images (Ferc, Vrtacnik, Blejec, \& Gril, 2003). 
The topic of molecular geometry involves spatial representation and is important in the understanding of the chemical and physical properties of molecules. Molecular structure affects molecular function. Recent studies by Cooper, Underwood, Hilley, \& Klymkowsky $(2010,2012)$ suggest that many students are unable to construct representations of simple molecular structures. Despite different teaching interventions (Gillespie, 2004), it continues to be one of the most challenging topics for the chemistry student. In this exploratory study, we decided to use the topic of the molecular structure and the comparison of three visualization techniques: physical models, PhET simulations, and Virtual Reality.

Physical molecular models allow students to create three-dimensional models in which atoms are represented by spheres of different colors, and bonds are represented by sticks between the spheres. Physical models are low tech and relatively inexpensive. The use of this tool is well documented in the chemistry education literature (Erlina, Cane, \& Williams, 2018; Jones, 2001; Pfennig \& Frock, 1999). They are useful for representing simple molecules; however, their utility for the representation of molecules is limited. It would be cumbersome and time consuming to use models to represent larger, more complex molecules. In addition, the models of larger molecules could be confusing due to the convolutedness of the models as well as being difficult and somewhat fragile to manipulate.

Computer simulations are tools that may help students in relating, interpreting, and making connections across multiple representations for the same object (Steiff \& Wilensky, 2003; van der Meij \& de Jong, 2006). $\mathrm{PhET}$ interactive simulations are research-based tools for teaching chemistry. The PhET interactive simulations project, hosted by the University of Colorado-Boulder, has developed numerous simulations for teaching chemistry, which are accessible for free online. These simulations are designed to focus on specific ideas and to allow students to explore those ideas through the chosen interactive components (Moore \& Perkins, 2014). Due to the fact that the physical molecular models (model kits) and simulations have been traditionally used as visualization tools, they could provide a baseline ("control") for the study.

While VR technology has been used commonly for entertainment purposes, such as gaming and 3-D theaters, it is gaining attention as an educational and training tool to provide learners with a safe environment, where they can learn and develop skills using virtual elements. Educational applications of VR can be found in medicine, nursing, biology, and chemistry education (Hansen, 2008).

In chemistry education, VR technology could facilitate the learning process by overcoming the major restrictions of traditional educational methods (Georgiou et al., 2007). The use of VR in education in general and also in chemistry is increasing in popularity. Thus far, the VR simulations have included experiences in 3-D molecular structure, chemical bonding, and intermolecular interactions in molecules (Jiménez, 2019). In their research, Dunnagan et al. (2020) evaluated the use of instrumentation in a VR setting and compared it with the use of the real instrument (infrared spectrophotometer) in an organic chemistry lab. The investigation found no significant difference in the learning outcomes between the two groups of students- those that were exposed to the physical instrument and the other group that worked in VR. Other research explored the use of VR technology in the understanding of the enzyme chorismate mutase mechanism and dynamics. A student survey showed that the students found the VR technology more engaging than the traditional approach (Bennie et al., 2019).

Companies such as Hyden-McNeil and Labster have developed VR labs in different areas of chemistry. Even though these labs need to be evaluated and their effect assessed, they could be useful when the attendance of students is challenging due to a pandemic that we are currently experiencing or other reasons that may prevent the students from attending the in-person lab.

Virtual reality technology provides a learner-centered approach, which supports constructivist learning. The technical capabilities of VR are aligned with constructive learning in terms of representation, active learning, and cognition (Chen, 2010). Virtual reality is capable of providing 3-D representations of concepts and processes, which allows students to be motivated and engaged in the learning process. Also, such representations provide individual experiences where learners are allowed to formulate their own perspectives and interpretations. In their research, Georgiou et al. (2007), compared of three chemical experiments: (i) volumetric analysis of acid from base and vice versa, (ii) complexometric neutralization and hardness estimation, and (iii) volumetric reduction-oxidation performed in a physical and VR lab. According to the 
authors the virtual lab contained a combination of hypermedia and virtual reality features. The authors are emphasizing that in terms of active learning, VR provides learners with a safe environment to freely explore and manipulate a problem, where making a mistake becomes a learning experience with the ability to adjust the situation and move forward with no risk. In such an environment, students learn by doing and constructing their own knowledge. Virtual Reality technology provides interactive, multidimensional visual forms of microscopic elements and allows the user to manipulate these elements in tactile ways, creating an experience that is not possible with other forms of representations (Georgiou et al., 2007).

The use of VR technology in education suggests that it is an effective tool in teaching topics that are proven difficult to carry out in traditional instructional settings and serves as a means of motivating and stimulating students' understanding of certain concepts (Shim et al., 2003; Limniou, Roberts, \& Papadopoulos, 2008). A quasi-experimental study that investigated the use of VR technology in enhancing students' learning of certain chemistry concepts such as molecular geometry concluded that students had an improved understanding of the 3-D nature of molecules if they did relevant activities in a VR environment compared to those students who used only 2-D images (Merchant et al., 2013).

In distance learning, VR technology is capable of providing students with interactive experiences regardless of their location at any time. This is a significant enhancement over common experiences limited to reading and watching videos or simulations. Virtual chemistry labs have been developed using VR technology, where students can access the lab and perform experiments multiple times, in a safe environment; VR labs could be a cost-effective alternative to traditional labs that are constrained by the cost, substance availability, number of trials and work hours (De Jong, Linn, \& Zacharia, 2013)

\section{Research questions}

RQ1: Which method, VR, simulations, or physical models, is more effective in helping students understand molecular geometry?

RQ2: What are students' opinions about the utility of VR in a chemistry course?

\section{Methods}

All ethical considerations common to research with human subjects were used in the development of this study. Prior to all phases, data collection and analysis protocols as well as security protocols were reviewed and approved by the University Institutional Review Board (IRB \# 1142901-1). Participation in the study was voluntary and opportunity to cease participation in the study was afforded to the participants. All the participants were required to complete a consent form at the beginning of this particular laboratory exercise.

\section{Participants}

The focus of this research study was an undergraduate general chemistry laboratory course at a mid-size, western U.S. public institution. The general chemistry course at this institution is taught as a two-semester, four-credit hour lecture, and one-credit hour laboratory each semester. The student population of this course consists of primarily chemistry, sports and exercise science, biology, pre-health, and dietetics majors.

The participants in this study were from three laboratory sections of the first semester general chemistry course. Each group was composed of 15 students. In order to minimize the instructor effect, all three sections were taught by the same instructor. The meeting time of each section was on different days. A traditional approach to teaching and learning was employed in the general chemistry laboratory at this institution. Students were not required to have prerequisite chemistry knowledge in order to enroll in this general chemistry lecture and laboratory course. 


\section{Data collection}

Data collection took place in the spring semester, 2018, toward the end of the semester with the experiment: Molecular Modeling. The students in each group were exposed to the concept of molecular modeling, though not in great detail, during lectures. Each of the three sections of lab explored the concept by using the same exercise but a different form of instruction. Group 1: composed of eight males and seven females that met at 11:00 am Tuesday morning performed the lab using the regular molecular model kits. Group 2: composed of nine males and six females that met on Wednesday at 2:00 pm was exposed to a PhET interactive simulation: “Molecular Modeling” (https://phet.colorado.edu/en/simulation/molecule-shapes). Group 3: composed of seven males and eight females that met on Thursday at 2:00 pm was exposed to molecules designed in VR. The sample of students is a convenient sample but also random since the students registered in one of the three sections at the beginning of the semester. The age of the students in these three groups varied between 18 and 25 years old.

Prior to beginning the experiment, the students in all three groups were presented with a demographic form (see Appendix 1) and the Purdue Visualization of Rotations Test (Bodner \& Guay, 1997). The Purdue Visualization of Rotation Test (PVRT) is a 20-question test. Students were presented with an example of rotation of a 3-D object and then asked to perform the same rotation on a different object and choose the results from five options. Students are allowed $10 \mathrm{~min}$ to complete the test. Furthermore, the students that participated in the VR exercise were asked additional yes/no questions in the form of a short survey regarding their familiarity with the VR technology (see Appendix 2). The students in each of the three groups were also asked to take a pre- and postinstruction test. The pre- and post-test was administered to the students with the purpose of measuring the difference of the participants' ability to solve the exercises correctly before and after using the assigned method and ultimately to assess the learning gains. The pre- and post-test was developed by the researchers and had identical content, asking questions regarding Lewis structure, electron domain, lone pair electrons, molecular geometry, dipole direction, and polarity of the following molecules: $\mathrm{H}_{2} \mathrm{~S}$, $\mathrm{PH}_{3}, \mathrm{CH}_{3} \mathrm{OH}, \mathrm{CS}_{2}$, and $\mathrm{CH}_{2} \mathrm{O}$. The chemistry instructor who taught the lab graded both tests at the end of the lab. The pre- and posttest are presented in Appendix 3.

During the Molecular Modeling Lab, students in all three groups were instructed to build several molecules, for example: $\mathrm{H}_{2}$, $\mathrm{BeCl}_{2}, \mathrm{CO}_{2}, \mathrm{HF}, \mathrm{H}_{2} \mathrm{CO}, \mathrm{SO}_{2}, \mathrm{CH}_{3} \mathrm{Br}, \mathrm{NH}_{3}, \mathrm{H}_{2} \mathrm{O}, \mathrm{PCl}_{5}, \mathrm{SF}_{4}, \mathrm{ClF}_{3}, \mathrm{SF}_{6}$, and $\mathrm{XeF}_{4}$. For each of these molecules, the students completed a table similar to the one presented in the test with information regarding the Lewis structure, electron domain, lone pair electrons, molecular geometry, dipole direction and polarity of the molecules. The learning activities were comparable across the three platforms: model kits, simulations (PhET), and VR.

In the designing of the experiment, the researchers consulted the PhET simulation and the same molecules were designed in VR. For the instruction using the VR technology, one of the researchers programmed the molecules. In this experiment, the VIVETM VIVE Virtual Reality System was used. The molecules were built by using open development engines and programs such as: Unity 3-D engine, Godot Engine, and Unreal Engine. Also, a unity software subscription to operate VIVE, that includes custom animations, editing tools, and tools that help track performance reports, was used in the designing of the molecular modeling lab in VR. Students who participated in the VR exercise received instruction and a short time for practicing with the controllers. At the end of the lab, the students in Group 3 were also asked to complete a short survey regarding their experience with VR (Appendix 4).

In all three lab sections, students worked in groups of two, and there was one group of three students. Regardless of the tool used, each group spent on average a total of $1.5 \mathrm{~h}$ working the practice problems. In VR, students switched roles while one of the students was in VR and the other or the others (the group of three) were following the work on a screen. Each group spent 15-20 min in VR.

For some students the VR exercise may look like a video game with molecules. Even though the exercise presented in different visualization techniques featured the same molecules, they are different in the visualization abilities. For example, the PhET simulations provides a 2-D display in comparison with the physical and VR models that expose the students to a 3-D representation. In comparison with the PhET simulations, the VR models provide students with a sense of immersion and realism.

\section{Data analysis}

To answer the first research question, the scores from the pre- and post-test were analyzed using Statistical Package for the Social Sciences (SPSS), and the mean and standard deviation for each group were reported. An analysis of covariance (ANCOVA) test was performed in order to determine if there is a significant difference among the pretest scores in three groups are correlated to the Purdue Visualization Test (PRVT) performance.

To answer the second research question, the students' comments in response to each open-ended question (see Appendix 4) in the VR survey were categorized. Another aspect of this research explored the participants' attitude towards the use of VR for this molecular modeling exercise. Since this is a qualitative aspect, we analyzed the data manually by grouping the responses into several themes. 


\section{Results and discussion}

The purpose of the current study was to examine the impact of three different interventions: use of models, simulations, and VR technology on general chemistry students' comprehension of different visual representations in chemistry. We present in this section participant demographics, the scores of the three groups on the PRVT, pre- and post-test scores, and the results of the ANCOVA statistical analysis, which compared the performance of the three groups using the PRVT as a covariance.

Among the students, 82\% (37 out of 45) were freshman. The age of the students varied between 18 and 25 . All of the students had taken at least one year of high school chemistry and four years of math. The gender distribution among the three research groups is presented in Appendix 1. All 45 students involved in this study took the Purdue Visualization of Rotation Test (PRVT). The mean and standard deviation for each group are presented in Table 1. Most of the students showed average or low rotational ability.

The students in Group 3 that participated in the VR exercise were asked additional yes/no questions regarding their experience with the VR technology (see Appendix 2). Even though all of them had heard of VR technology, only six of them had ever entered the virtual world and only two of them had spent a lot of time exploring the VR gaming.

Descriptive statistics regarding the pre- and post-test performance and knowledge gain (Post-test score Pre-test score) by the three groups are presented in Table 2. Participants received one point for every question answered correctly with a possible total of 30 points.

Through the statistical analysis we explored several questions: Is there a difference between the pre-test scores among the three groups? Is there a difference between the post-test scores among the three groups? Is there a difference in knowledge gain among the three groups? Based on the analysis between the pre-test score among the three groups, the F-statistic and the corresponding $p$-value for pre-test are: $F(2,42)=0.261$ and $p=0.771$ and for post-test: $F(2,42)=1.684$ and $p=0.198$. The means of pre- and post-test within each group show improvement in the students' knowledge. Each student in the three groups gained knowledge as a result of the experiment, but the statistical analysis indicates there is not a significant difference in the knowledge gain among the three groups. The posttest means and gains among all three groups in addition to paired groups (1 and 2, 2 and 3,1 and 3) were analyzed, and there is no significant difference in the knowledge gain of the groups for this particular experiment.

Another question addressed: Do the PRVT scores impact the outcomes of the interventions applied to each group? To answer this question, we explored the effect of the PRVT scores on the knowledge gain for each group. Table 3 displays the results of the analysis of covariance (ANCOVA) using PRVT score as covariate. The

Table 1: Performance on the PRVT test of the three group.

\begin{tabular}{lrr}
\hline & Mean & SD \\
\hline Group 1: Models & 8.33 & 3.11 \\
Group 2: PhET simulation & 8.46 & 2.21 \\
Group3: VR & 8.20 & 2.58 \\
\hline
\end{tabular}

Table 2: Descriptive statistics of pre- and post- test and knowledge gain.

\begin{tabular}{|c|c|c|c|c|c|c|c|}
\hline \multirow[t]{2}{*}{ Group \# } & \multirow[t]{2}{*}{$N$} & \multicolumn{2}{|c|}{ Pre-test } & \multicolumn{2}{|c|}{ Post-test } & \multicolumn{2}{|c|}{ Knowledge gain } \\
\hline & & Mean & SD & Mean & SD & Mean & SD \\
\hline Group1: Models & 15 & 12.86 & 3.33 & 25.80 & 2.27 & 12.93 & 3.15 \\
\hline Group2: PhET simulation & 15 & 11.73 & 2.40 & 22.60 & 3.52 & 10.87 & 2.64 \\
\hline Group3: VR & 15 & 11.20 & 1.86 & 23.87 & 2.94 & 12.67 & 2.38 \\
\hline
\end{tabular}

$\mathrm{SD}=$ Standard deviation. 
results indicated that there was no statistically significant difference between the three study groups: $F(2$, 42) $=2.44$ and $p=0.1$.

The ANCOVA test was conducted on the three sets of data (pre and post of each intervention group) and the results of the PRVT were considered as "covariate". ANCOVA is an appropriate test to compare three groups and explore the possibility of the difference between the groups due to a certain intervention but also the effect of students' performance on the PRVT on the knowledge gain among the three groups.

Considering our assumption that VR will have a higher effect on the student understanding of models, the lack of significant difference among the three groups was surprising. This led us to conclude that for such a task as molecular modeling, the models are an effective, inexpensive way to enhance student understanding. Simulations could equally help students understand the molecular geometry. Literature shows that the simulations are especially helpful for high school students who lack the experience of learning with different visual representation formats in chemistry (Urhahne, Nick, \& Schanze, 2009). Also, we were surprised by the lack of correlation between student's visual ability and their performance regardless of the intervention. According to these results, it appears that spatial ability is not necessarily a strong predictor of scientific problem-solving ability at least as it relates to this particular type of exercise. These results are consistent with recent studies (Steiff et al., 2018; Steiff, Ryu, Dixon, \& Hegarty, 2012) that suggest students do not rely solely on their spatial abilities to solve problems, but rather they use algorithms that help them transform diagrams to solve problems.

The authors observed a greater degree of student immersion, enjoyment, and fascination using VR as opposed to the other tools employed for the exercise. Additionally, the students expressed the desire to have the VR program available for additional work. This indicated motivation by the students to spend more of their own time to learn the concepts involved within the exercise. While the VR may invoke novelty or the "cool factor," it was observed that students appeared to be interested and willing to spend more time on the exercise, which is conducive to learning and understanding the concepts. It was found that students had positive opinions and demonstrated excitement toward the use of VR in a chemistry class and its effectiveness in learning certain visual chemistry concepts. About $73 \%$ (11 out of 15) found the use of VR "exciting" and "helpful" in understanding the topic. Students commented on the VR's ability to provide "an accurate depiction of the molecules," and how it makes it "easy to visualize and interact with the molecules." One participant stated that the use of VR could "help students learn in online classes and distance learning." The general impression about VR in helping the students understand the molecular geometry was positive. One of the challenges of this study was the lack of prior experience using VR. Regarding students' suggestions, about $80 \%$ of the participants recommended making the VR available and accessible outside class time, to be able to practice and learn chemistry concepts. In our department, we opened a VR lab where the students can attend at certain times of the day to practice and learn in VR. Many of the students that participated in this study came to the VR lab after the molecular modeling exercise to practice more on the exercises.

\section{Conclusions and implications for teaching}

In this study the utility of virtual reality in molecular modeling was investigated and compared to two other methods usually used as aids in visualization.

Table 3: Summary of ANCOVA results for comparisons between the three groups' knowledge gain when PRVT was used as a covariate.

\begin{tabular}{lrrrrr}
\hline Group & SSM & $\boldsymbol{d f}$ & MS & $\boldsymbol{F}$ & $\boldsymbol{p}$ \\
\hline Intercept & 659.034 & 1 & 659.034 & 85.718 & 0.000 \\
PRVT & 0.775 & 1 & 0.775 & 0.101 & 0.753 \\
Intervention type & 37.518 & 2 & 18.759 & 2.440 & 0.100 \\
Error & 315.225 & 41 & 7.688 & & \\
\hline
\end{tabular}


Although these results are preliminary, they are the first step in a research program to investigate the utility of virtual reality in chemical education. Overall the students suggested a benefit for using VR when learning about the relation between 3-D and 2-D representations in chemistry. The VR technology will allow the chemistry students to have a natural "physical interaction" and 3-D exploration of the molecular structures. Students have the opportunity to "touch", manipulate, rotate, analyze, and become immersed in their 3-D models. As researchers one of the main challenges we faced was to program and develop the exercises in VR. This challenge was mitigated by an interdisciplinary collaboration, working as a team where the researchers brought together the knowledge of chemistry and programming. The cost of VR technology is also a consideration. However, since we started the work, the cost of VR technology has become more affordable, and it probably will not be long until VR will become standard equipment in the lecture halls.

This study may offer several implications for teaching and learning chemistry. In addition to providing a general guideline of how to effectively utilize VR in teaching certain chemistry concepts, the results of this study could aid chemistry instructors in a variety of classroom settings, face to face, hybrid, and online classes. This could also apply to more complex phenomena such as reaction mechanisms and stereochemistry. We observed that using the VR technology made the learning and lab exercise of molecular modeling more interesting and exciting for the students. The design of the molecules in VR may spark student's creativity, active learning, and engagement. The students that used the VR had the feeling that they were "walking among molecules." The 3-D molecules appeared as real objects and students tried to "grab" them. We are still in the beginning of exploration of using VR technology for educational purposes especially in chemistry.

Prior to initiating the study, possible gains in post-test achievement for the VR groups were anticipated. We hypothesized that working in VR would enhance students' performance and understanding of molecular geometry due to the unique interaction and manipulation of molecules and also due to the gaming aspect of the technology. We did not find a significant difference among the three tools of visualization. However, based on student enthusiasm, reaction to the exercise, and many questions that were asked after the performance of the exercise in VR, it appears that this technology has the potential of becoming a powerful addition to the visualization tools to facilitate student understanding of chemical phenomena that are difficult to understand without visualization or even with the traditional, more established visualizations tools. The benefit of VR in this exercise appeared to be the enhanced engagement of the students. The students in Group 3 demonstrated a pronounced excitement and involvement in performing the exercises.

Based on the observations and results of this experiment that the students performed somewhat equally well regardless of the tools used, the authors consider the utility of VR would be better suited for complex processes that are more difficult to visualize. Exercises involving concepts such as enzyme-substrate binding, reaction mechanisms (especially those involving stereochemistry in which there are prochiral centers), and substrate specificity are difficult to visualize using simulations and practically impossible as well as cumbersome using physical models. We are currently developing VR activities exploring the mechanisms of several reactions in the Krebs cycle including aconitase and malate dehydrogenase to assess the utility of VR versus simulations.

Acknowledgments: The authors would like to thank Dalal Alrmuny for her contribution to the literature review and to the students who participated in this research.

Author contribution: All the authors have accepted responsibility for the entire content of this submitted manuscript and approved submission.

Research funding: None declared.

Conflict of interest statement: The authors declare no conflicts of interest regarding this article. 


\section{Appendix 1}

\section{Demographic form}

Name:

Academic Major:

Year you graduated from high school:

Year of study:

$\square$ freshman

$\square$ sophomore

$\square$ junior

$\square$ senior

$\square$ returning for 2nd degree

Years of science:

Years of math:

If returning for second degree, what was first degree?

Table 1: Gender representation in the three researched groups:

\begin{tabular}{lrr}
\hline Group & Male & Female \\
\hline Group 1: Models & 8 & 7 \\
Group 2: PhET simulation & 9 & 5 \\
Group 3: VR & 6 & 9 \\
\hline
\end{tabular}

\section{Appendix 2}

Students that participated in the VR exercise were asked additional yes/no questions

Table 2: Additional questions asked to the Group 3 of students:

I have never heard of VR

I have heard about it but never entered the virtual

\section{0}

I am familiar with VR but I consider myself a beginner

I have spent a lot of time exploring VR gaming experience

Yes/No responses

\section{Appendix 3}

\section{Pre- and post- test:}

\section{CHEM111-Lab}

Name

Complete the following for each of the molecules: 


\begin{tabular}{|c|c|c|c|c|c|c|}
\hline Molecule & Lewis structure & Electron domain & Lone pair & Molecular geometry & Dipole direction & Polarity \\
\hline \multicolumn{7}{|l|}{$\mathrm{H}_{2} \mathrm{~S}$} \\
\hline \multicolumn{7}{|l|}{$\mathrm{PH}_{3}$} \\
\hline \multicolumn{7}{|l|}{$\mathrm{CH}_{3} \mathrm{OH}$} \\
\hline \multicolumn{7}{|l|}{$\mathrm{CS}_{2}$} \\
\hline $\mathrm{CH}_{2} \mathrm{O}$ & & & & & & \\
\hline
\end{tabular}

Key for the exercise:

\begin{tabular}{|c|c|c|c|c|c|c|}
\hline Molecule & Lewis structure & Electron domain & Lone pair & Molecular geometry & Dipole direction & Polarity \\
\hline $\mathrm{H}_{2} \mathrm{~S}$ & $\mathrm{H}-\mathrm{S}_{\bullet}-\mathrm{H}$ & 4 & 2 & & & Polar \\
\hline $\mathrm{PH}_{3}$ & $-\mathrm{P}-\mathrm{H}$ & 4 & 1 & $P$ & & Polar \\
\hline $\mathrm{CH}_{3} \mathrm{OH}$ & $-\mathrm{c}-\mathrm{O}:$ & 4 & 0 & & & Polar \\
\hline $\mathrm{CS}_{2}$ & $\therefore S=C=S^{\circ}$ & 2 & 0 & & & Non-polar \\
\hline $\mathrm{CH}_{2} \mathrm{O}$ & $\prod_{\mathrm{H}-\mathrm{O}}^{\mathrm{O}:}$ & 3 & 0 & & & Polar \\
\hline
\end{tabular}

\section{Appendix 4}

(1) Was VR helpful in understanding the topic? If so, how?

(2) What suggestions can you make regarding the use of VR for this topic?

(3) How can the use of VR be made more compatible for your use?

(4) Any other comments?

\section{Appendix 5 Photograph of student working in VR}

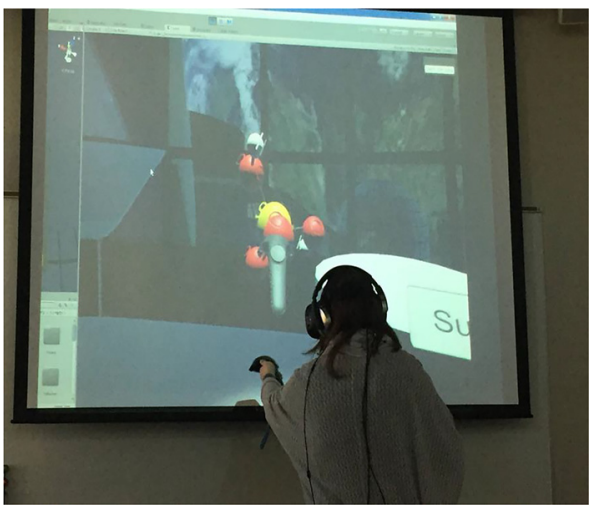


Links to our work in VR- designed by one of the authors.

https://www.youtube.com/watch?v=NrdPa9KXAYA\&feature=youtu.be

https://www.youtube.com/watch?v=5_

r06AJJ2Xc\&list=PLnHDp1PnNwvJEKyKaArpJZIFt3XAKv0f6\&index=5

\section{References}

Abraham, M., Varghese, V., \& Tang, H. (2010). Using molecular representations to aid student understanding of stereochemical concepts. Journal of Chemical Education, 87(12), 1425-1429.

Arneson, J. B., \& Offerdahl, E. G. (2018). Visual literacy in Bloom: Using Bloom's taxonomy to support visual learning skills. CBE-Life Sciences Education, 17, 1.

Bennie, S. J., Ranaghan, K. E., Deeks, H., Goldsmith, H. E., O’Connor, M. B., Mulholland, A. J., Glowacki, D. R. (2019). Teaching enzyme catalysis using interactive molecular dynamics in virtual reality. Journal of Chemical Education, 96(11), 2488-2496.

Bodner, G. M., \& Guay, R. B. (1997). The Purdue visualization of rotations test. Chemical Educators, 2(4), 1-17.

Chen, C. J. (2010). Theoretical bases for using virtual reality in education. Themes in Science and Technolog1y Education, 2(1-2), 7190. Retrieved from http://files.eric.ed.gov/fulltext/E)113.

Clark, R. C., \& Mayer, R. E. (2008). E-learning and the and science of instruction. (2 ed.) San Francisco: Pfeiffer, John Wiley \& Sons.

Clauss, A. D., \& Nelsen, S. F. (2009). Integrating computational molecular modeling into the undergraduate organic chemistry curriculum. Journal of Chemical Education, 86(8), 955-958.

Cooper M., Underwood S., Hilley C., \& Klymkowsky M. (2010). Lost in Lewis structures: An investigation of student difficulties in developing representational competence. Journal of Chemical Education, 7(8), 869-874.

Cooper M., Underwood S., Hilley C., \& Klymkowsky M. (2012). Development and assessment of a molecular structure and properties learning progression. Journal of Chemical Education, 89(11), 1351-1357.

De Jong, T., Linn, M. C., \& Zacharia, Z. C. (2013) Physical and virtual laboratories in science and engineering education. Science, 340(6130), 305-308.

Dori, Y. J., \& Barak, M. (2001). Virtual and physical molecular modeling: Fostering model perception and spatial understanding. Educational Technology \& Society, 4(1), 61-74. ISSN: 1436-4522.

Dunnagan, C. L., Dannenberg, D. A., Cuales, M. P., Earnest, A. D., Gurnsey, R. M., \& Gallardo- Williams, M. T. (2020). Production and evaluation of a realistic immersive virtual reality organic chemistry laboratory experience: infrared spectroscopy. Journal of Chemical Education, 97(1), 258-262.

Erlina, P., Cane, C., \& Williams, D. P. (2018). Prediction! The VSEPR Game: Using cards and molecular model building to actively enhance students' understanding of molecular geometry. Journal of Chemical Education, 95(6), 991-995.

Ferc, V., Vrtacnik, M., Blejec, A., \& Gril, A. (2003). Students' understanding of molecular structure representations. International Journal of Science Education, 25(10), 1227-1245.

Freina, L., \& Ott, M. (2008). A Literature review on immersive virtual reality in education: State of the art and perspective. In The international scientific conference e-learning and software for education (Vol. 1) (p. 133). "Carol I" National Defence University (2015).

Georgiou, J., Dimitropoulos, K., \& Manitsaris, A. (2007). A virtual reality laboratory for distance education in chemistry. International Journal of Social Science, 2(1), 34-41. Accession \#27963853.

Gillespie, R. J. (2004). Teaching molecular geometry with the VSEPR model. Journal of Chemical Education, 81(3), 298.

Griffiths, A., \& Preston, K. (1992). Grade 12 students' misconceptions relating to fundamental characteristics of atoms and molecules. Journal of Research in Science Teaching, 29, 611-628.

Hansen, M. (2008). Versatile, immersive, creative and dynamic virtual 3-D healthcare learning environments: A review of the literature. Journal of Medical Internet Research, 10(3), 26.

Harle, M., \& Towns, M. (2011). A review of spatial ability literature, its connection to chemistry, and implications for instruction. Journal of Chemical Education, 88, 351-360.

Harle, M., \& Towns, M. H. (2012). Students' understanding of external representations of the potassium ion channel protein part II: structure-function relationships and fragmented knowledge. Biochemistry and Molecular Biology Education, 40(6), $357-363$.

Jiménez Z. A. (2019). Teaching and learning chemistry via augmented and immersive virtual reality. ACS Symposium Series, 1318(3), 31-52.

Jones, L. L., Jordan, K. D., \& Stilling, N. A. (2005). Molecular visualization in chemistry education: The role of multidisciplinary collaboration. University Chemistry Education, 6(3), 136-149.

Jones, L. L., \& Kelly, R. M. (2015). Visualization: The key to understanding chemistry concepts. ACS Symposium Series, 1208(8), 121-140.

Jones, M. B. (2001). Molecular modelling in the undergraduate chemistry curriculum. Journal of Chemical Education, 78(7), 867-868. 
Limniou, M., Roberts, D., \& Papadopoulos, N. (2008). Full immersive virtual environment CAVETM in chemistry education. Computers \& Education, 51(2), 584-593.

Merchant Z., Goetz, E. T., Keeney-Kennicutt, W., Cifuentes, L., Kwok, O. M., \& Davis, T. J. (2013). Exploring 3-D virtual reality technology for spatial ability and chemistry achievement. Journal of Computer Assisted Learning, 29(6), 579-590.

Moore, E. B., \& Perkins, K. K. (2014). Assessing the implicit scaffolding design framework: Effectiveness of the Build a Molecule simulation. In Proceedings of the National Association for Research in Science Teaching (NARST), Annual International Conference. Pittsburgh, PA.

Oliver-Hoyo, M., \& Babilonia-Rosa, M. A. (2017). Promotion of spatial skills in chemistry and biochemistry education at the college level. Journal of Chemical Education, 94(8), 996-1006.

Pfennig, B. W., \& Frock, R. L. (1999). The use of molecular modeling and VSEPR theory in the undergraduate curriculum to predict the three-dimensional structure of molecules. Journal of Chemical Education, 76(7), 1018-1022.

Piaget, J. (2001). The psychology of intelligence. Oxford, UK: Routledge.

Pribyl, J. R., \& Bodner, G. M. (1987). Spatial ability and its role in organic chemistry: A study of four organic courses. Journal of Research in Science Teaching, 24(3), 229-240.

Ruddick, K. R., Parrill, A. L., \& Petersen, R. L. (2012). Introductory molecular orbital theory: An honors general chemistry computational lab as implemented using three-dimensional modeling software. Journal of Chemical Education, 89(11), 1358-1363.

Sanger, M. J., Phelps, A. J., \& Fienhold, J. (2000) Using a computer animation to improve students' conceptual understanding of a can crushing demonstration. Journal of Chemical Education, 77(11), 1517-1519.

Shim, K. C., Park, J. S., Kim, H. S., Kim, J. H., Park, Y. C., \& Ryu, H. I. (2003). Application of virtual reality technology in biology education. Journal of Biological Education, 37(2), 71-74.

Steiff, M., \& Wilensky, U. (2003). Connected chemistry. Incorporating interactive simulations into the chemistry classroom. Journal of Science Education and Technology, 12(3), 285-302. ISSN: 1059-0145.

Stieff, M., Ryu, M., Dixon, B., \& Hegarty, M. (2012). The role of spatial ability and strategy preference for spatial problem solving in organic chemistry. Journal of Chemical Education, 89(7), 854-859.

Stieff, M., Origenes, A., DeSutter, D., Lira, M., Gabel, G., \& Banevicius, L. (2018). Operational constraints on the mental rotation of STEM diagrams. Journal of Educational Psychology, 110(8), 1160-1174.

Taber, K. (2002). Chemical misconceptions-prevention, diagnosis and cure (p. 420). London: Royal Society of Chemistry. ISBN $085404390 \mathrm{X}$

Towns, M. H., Raker, J. R., Becker, N., Harle, M., \& Sutcliffe, J. (2012). The biochemistry tetrahedron and the development of the taxonomy of biochemistry external representations (TOBER). Chemistry Education Research and Practice, 13(3), 296-306.

van der Meij, J., \& de Jong, T. (2006). Supporting student's learning with multiple representations in a dynamic simulation-based learning environment. Learning and Instruction, 16(3), 199-212.

Urhahne, D., Nick, S., \& Schanze, S. (2009). The effect of three-dimensional simulations on the understanding of chemical structures and their properties. Research in Science Education, 39, 495-513.

Wu, H. K., Krajcik, J. S., \& Soloway, E. (2001). Promoting understanding of chemical representations: Students' use of a visualization tool in the classroom. Journal of Research in Science Teaching, 38(7), 821-842.

Wu, H. K., \& Shah, P. (2004). Exploring visuospatial thinking in chemistry learning. Research in Science Education, 88(3), $465-492$. 